\title{
Evaluation of the Hypolipidemic and Antioxidant Activities of Chloroformic Extract from Vangueria infausta Leaves in Rats with Hyperchloesterolemia
}

\author{
Fatma Abdel-Azim Sanad
}

National Organization for Drug Control and Research, P.O. 29 Dokki, Cairo, Egypt

Received: 10 June 2020 / Accepted 15 August 2020 / Publication date: 30 August 2020

\begin{abstract}
The aim of the current study was to evaluate the hypolipidemic effects of chloroformic extract from Vangueria infausta leaves in rats maintained on high cholesterol diet (HCD)-induced hyperlipidemia. The extract was orally given by intragastric tube at a low dose $(125 \mathrm{mg} / \mathrm{kg})$ and high dose $(250$ $\mathrm{mg} / \mathrm{kg}$ ) once daily for 3 weeks. The administration of HCD resulted in a significant increase in the serum levels of TC, TG, LDL-C, V-LDL-C, atherogenic index (AI) value, hepatic MDA and a significant decline in HDL-C and liver GSH level as compared to their corresponding controls, $P<$ 0.05 . The treatment with the lowest dose did not produce any significant change in the pattern of lipid profile, $P>0.05$. While the highest dose of the extract revealed a significant decline in the serum TC, TG, LDL-C, V-LDL-C levels, atherogenic index (AI) value, hepatic MDA and a significant increase in HDL-C as well as liver GSH level as compared to HCD-treated rats, $P<0.05$. In addition, the highest dose showed no significant difference in comparison with that the reference drug (Atorvastatin) used in this study. Moreover, histopathological examinations reinforced the biochemical data. In conclusion, the $V$. infausta extract was found to enjoy hypolipidemic activity in hyperlipidemic rats can be applied as a phytomedicine in the management of the cardiovascular diseases.
\end{abstract}

\section{Keywords: $V$. infausta extract, High cholesterol diet, TC, TG}

\section{Introduction}

The profound role of hyperlipidemia, particularly hypercholesterolemia leading to cardiovascular diseases have been widely investigated in many previous studies (Binno, 2016). Hyperlipidemia is one of the commonest metabolic diseases in developed countries and has become a global epidemic at an alarming rate. According to WHO reports, hyperlipidemia is associated with more than 50\% global prevalence of ischemic heart diseases (Mutangadura, 2004).

The 3-hydroxy-3-methylglutaryl coenzyme A (HMG-CoA) reductase inhibitors-statins have been the choice of frontline treatment for controlling hypercholesterolemia over the past twenty years (Sehra et al., 2017). However, many recent reports have come up recently data achieved from clinical studies divulging the side effects of statins. Thus, there is necessity to search for safer drugs with lipid lowering and antioxidant activities with no side effects (Clarke et al., 2016).

There has been an increasing interest in natural products and their importance in the conservation and improvement of fitness and wellness. The cholesterol-lowering effect of nutritive plants has been well investigated and numerous plants were revealed to be helpful in bringing down plasma cholesterol levels and encouraging safety profile (Choudhary et al., 2005).

$V$. infausta Burch (family Rubiaceae) is a tree 2-7 meters tall, it is a member of the Rubiaceae family, has a worldwide distribution, grows well on Angola, Botswana, Kenya, Malawi, Mozambique, Namibia, Rwanda, South Africa, Swaziland, Tanzania, Uganda, Zambia and Zimbabwe and it is native to southern Africa and also East Africa, and Madagascar (Maroyi, 2018). Its fruits are eaten by both people and wild animals, whereas different parts of this plant have been used in traditional medicine for treatment of malaria, menstrual, uterine problems, wounds, and genital swellings among others (Chhabra et al., 1984).

The antioxidant activity of methanol extract from $V$. infausta leaves has been investigated by (El-Tantawy et al., 2011). The extract revealed hepatoprotective and pancreatic protective effects. In the present study, we aimed to evaluate the hypolipidemic and antioxidative effects of chloroformic extract from $V$. infausta leaves in high-cholesterol diet-induced hyperlipidemia in male Wistar rats.

Corresponding Author: Fatma Abdel-Azim Sanad, National Organization for Drug Control and Research, P.O. 29 Dokki, Cairo, Egypt. E-mail: fatmaazimm@yahoo.com 


\section{Materials and Methods}

\section{Plant material and extraction}

Samples of V. infausta leaves were purchased from El-Zoharya Garden, Ministry of Agriculture, Cairo, Egypt. The fresh cut plants were allowed to dry in the drying room with active aeriation at ambient temperature and packed in paper bags. Dried plants were ground with sample mill and approximately (500 g of powder) in turn were extracted with the chloroform. The extract was evaporated to dryness under vacuum using a rotary. The procedure of soaking and evaporation was repeated until exhaustion of the plants powder, and then the remainders were combined and weighed.

\section{Phytochemical analysis of extract using GC-MS}

GC analysis: The analysis was achieved utilizing a GC (Agilent Technologies 7890A) interfaced with a mass selective detector (MSD, Agilent 7000) equipped with a polar Agilent HP-5ms (5\%-phenyl methyl poly siloxane) capillary column $(30 \mathrm{~m} \times 0.25 \mathrm{~mm}$ i. $\mathrm{d}$. and $0.25 \mu \mathrm{m}$ film thickness).

Helium (linear velocity of $1 \mathrm{~mL} / \mathrm{min}$ ) was used as the carrier gas. The injector and detector temperatures were adjusted to $200^{\circ} \mathrm{C}$ and $250^{\circ} \mathrm{C}$, respectively. Sample injection volume was $1 \mu \mathrm{L}$. The MS operating parameters were as follows: ionization potential $70 \mathrm{eV}$, interface temperature 250 ${ }^{\circ} \mathrm{C}$, and acquisition mass range 50-800 (Santana et al., 2013). Identification of the components was accomplished by comparing their mass spectra and retention time with those of the genuine compounds and by computer cross-referencing with NIST and WILEY library in addition to comparison of the fragmentation pattern of the mass spectral data with reported values.

\section{Acute toxicity study}

Male Wistar rats weighing (120-150 g) were used for the acute toxicity study, and the LD $_{50}$ of chloroformic extract from $\mathrm{V}$. infausta leaves under investigation was determined according to the method described by Behrens and Karber (Behrens and Karber, 1970). It was found that the tested fraction was not mortal even at a dose of $2,500 \mathrm{mg} / \mathrm{kg}$ and consequently both doses of 125 and 250 $\mathrm{mg} / \mathrm{kg}$ were selected for the study.

\section{Animals and experimental design}

Thirty male Wister albino rats weighing 150-200 g were used for this study. The animals were kept in a temperature $\left(25 \pm 1{ }^{\circ} \mathrm{C}\right)$, humidity-controlled room, and a 12-h light-dark cycle (lights on at 0600 hours). Rats were allowed free access to tap water and standard pellet diet. Dietary composition used AIN-76A rodent diet. High cholesterol diet (HCD) composed of standard diet containing $4 \%$ cholesterol, $20 \%$ hydrogenated vegetable oil $\mathrm{ml} 0.25 \%$ cholic acid.

The institutional animal ethics committee approved all experimental protocols under the number 4/211/2017. The animals were classified into 5 groups, each of the six as follows:

Control (C): Rats were kept on standard pellet diet.

High cholesterol diet treated rats (HCD): Rats were kept on HCD containing $4 \%$ cholesterol, 20\% hydrogenated vegetable oil $\mathrm{ml} 0.25 \%$ cholic acid for 8 weeks (El-Tantawy et al. 2015).

HCD+ low dose of chloroformic extract (HCD+LDCE): rats with HCD were orally administered $125 \mathrm{mg} / \mathrm{kg}$ of chloroformic extract by stomach tube once daily for a period of 3 weeks.

HCD+ high dose of chloroformic extract (HCD+HDCE): rats with HCD were orally administered $250 \mathrm{mg} / \mathrm{kg}$ of chloroformic extract by stomach tube once daily for a period of 3 weeks).

HCD+ Atorvastatin (reference drug10 $\mathbf{~ m g} / \mathbf{~ k g})(\mathbf{H C D}+\mathbf{A})$ : rats with HCD were orally administered $10 \mathrm{mg} / \mathrm{kg}$ of Atorvastatin by stomach tube once daily for a period of 3 weeks (Ahmed et al. 2019).

\section{Biochemical assay}

On day 22, the rats were sacrificed by cervical decapitation under mild anesthesia. Animals were fasted overnight, blood samples were withdrawn from the retro-orbital vein using a glass capillary tube. The blood samples allowed to coagulate and then centrifuged at $3500 \mathrm{rpm}$ for $15 \mathrm{~min}$. The separated sera samples were used for the evaluation of alanine transaminase (ALT), aspartate transaminase (AST), albumin, total protein, urea and creatinine using commercial kits from 
Biodiagnostic, Cairo, Egypt. In addition, triglycerides (TG), total cholesterol (TC), high densitylipoprotein cholesterol (HDL-C) levels were estimated using commercial kits purchased from (Biodiagnostic, Cairo, Egypt). Low density lipoprotein (LDL-C) is calculated according to the equation; LDL-C= TC-HDL-C-TG/5 (Friedewald et al., 1972). Atherogenic index (AI) was calculated from the equation: $\mathrm{AI}=(\mathrm{TC}-\mathrm{HDL}-\mathrm{C}) / \mathrm{HDL}-\mathrm{C}$. Very Low density lipoprotein (VLDL-C) was calculated by dividing $\mathrm{TG} / 5$.

\section{Preparation of liver homogenate for determination of GSH and MDA}

The liver was excised, accurately weighed and homogenized in ice-saline to prepare a $10 \%$ $(w / v)$ tissue homogenate. The homogenate was used for the evaluation of glutathione (GSH) and malondialdehyde (MDA) levels. Level of GSH in liver tissue was estimated by the method of (Ellman, 1959) using 5, 5'-dithiobis-(2-nitrobenzoate) at $412 \mathrm{~nm}$. MDA, a stable product of lipid peroxidation was measured by method of (Ohkawa et al., 1979). Shortly, $0.5 \mathrm{ml}$ of homogenate was mixed with $2.5 \mathrm{ml}$ of $20 \%$ trichloroacetic acid and centrifuged at $3000 \mathrm{rpm}$ for $10 \mathrm{~min}$. The supernatant was decanted and the precipitate was washed once with $0.05 \mathrm{M}$ sulphuric acid and then 3 $\mathrm{ml}$ of $0.2 \mathrm{~g} / \mathrm{dl}$ thiobarbituric acid reagent was added to the precipitate. The mixture was boiled in a water bath for $30 \mathrm{~min}$. After cooling by putting in a cold water, the subsequent chromogen was removed with $4 \mathrm{ml}$ of n-butyl alcohol. The organic phase was separated by centrifugation at $3500 \mathrm{rpm}$ for $15 \mathrm{~min}$ and absorbance was recorded at wavelength of $530 \mathrm{~nm}$.

\section{Histopathological assessment}

Liver tissues from all groups were dissected out rapidly, washed with cold saline, and fixed in $10 \%$ neutral buffered formalin, dehydrated with $50-100 \%$ ethanol solutions, and embedded in paraffin. Sections $(4-5 \mu)$ were cut and stained with hematoxylin-eosin.

\section{Statistical analysis}

Results are expressed as mean \pm S.E. for each group. Statistical analysis was performed using SPSS 18.0 for Windows (Chicago, IL, USA). For multiple comparisons, one-way analysis of variance (ANOVA) was used. In cases where ANOVA showed significant differences, post hoc analysis was performed followed by Tukey's multiple comparison test. $P<0.05$ considered significant.

\section{Results}

\section{Phytochemical investigations of $V$. infausta chloroformic extract}

GC analysis of the chloroform extract from $V$. infausta identified 21 compounds and many classes of compounds were detected. Polyunsaturated fatty acids: were one of the most abundant category of identified compounds as they accounted for $37.74 \%$. The main compound was CisVaccenic acid (22.91\%). Saturated fatty acids, accounting for $30.25 \%$, was the second main class and the major compound was palmitic acid, which represented $7.31 \%$. In addition, triterpenes, hydrocarbons, and oxygenated compounds accounted for $22.03 \%, 8.82 \%$, and $1.16 \%$ respectively, Table (1). Chromatograms of the compounds and their retention times are presented in Fig (1).

\section{Effect of $V$. infausta extract treatment on serum lipid profile}

Administration of HCD to rats caused a significant increase in TC, TG, LDL-C, V- LDL-C levels, AI value and a significant decline in HDL-C concentration as compared to their corresponding control animals, $P<0.05$. Treatment of HCD with a low dose of $V$. infausta extract revealed a significant decrease $(P<0.05)$ in the levels TC, TG only and showed insignificant change in the values of the remaining parameters in comparison with that of HCD-treated rats, $P>0.05$. Concerning the treatment with the high dose of the extract as well as reference drug (Atorvastatin), both of them produced a significant decrease in TC, TG, LDL-C, V- LDL-C, levels, AI value and a significant rise in HDL-C level when compared to that of HCD-treated animals, $P<0.05$. Both of the high dose of the extract and the reference displayed significant changes as compared to that of the low dose, $P<0.05$. No significant difference could be detected between the high dose of the extract as well as the reference drug, $P>0.05$, Table (2). 
Table 1: Chemical composition of chloroformic extract from Vangueria infausta subjected to GC analysis

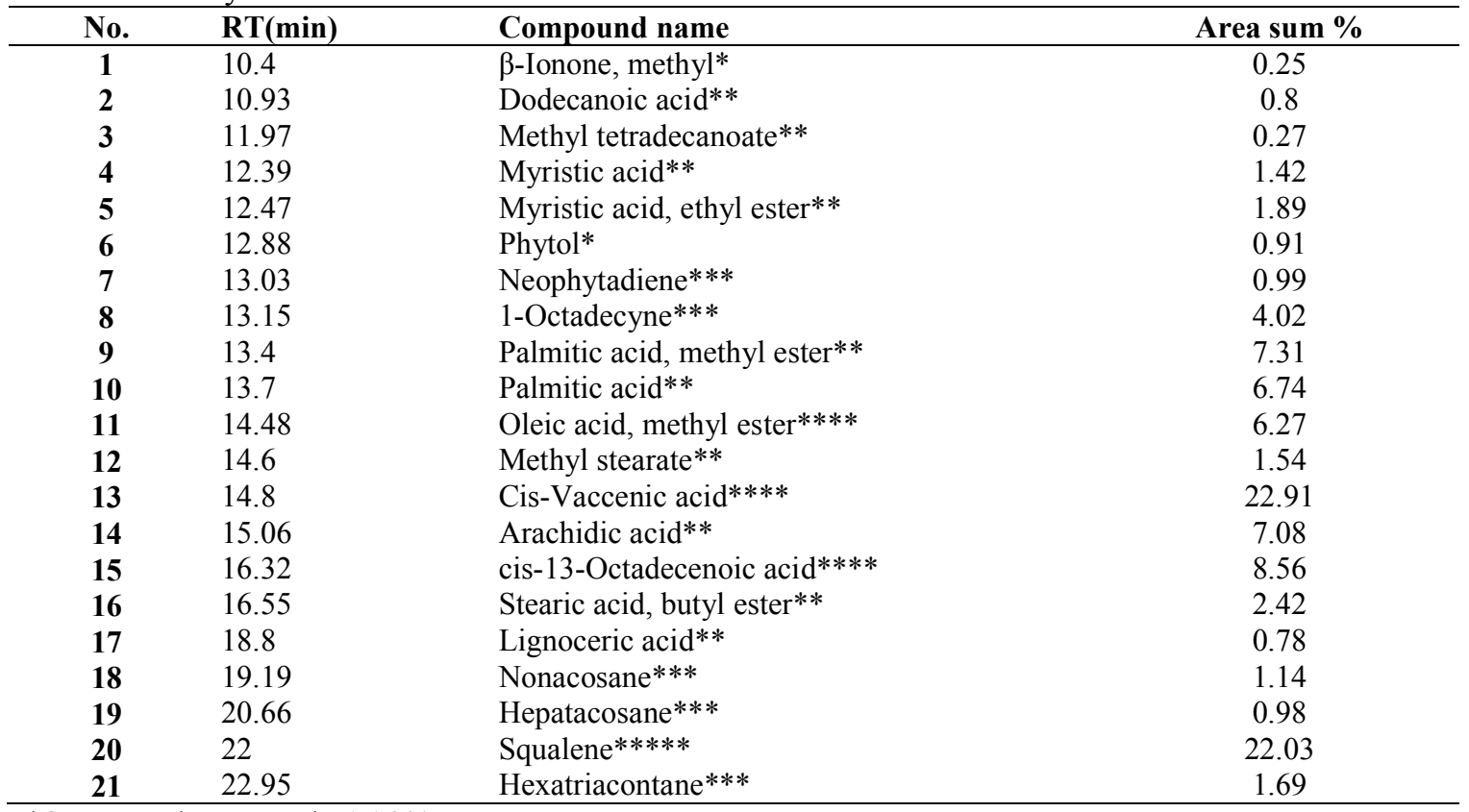

*Oxygenated compounds: $1.16 \%$

**Saturated fatty acids: $30.25 \%$

***Hydrocarbons: $8.82 \%$

$* * * *$ Omega fatty acids: $37.74 \%$

$* * * * *$ Triterpene: $22.03 \%$

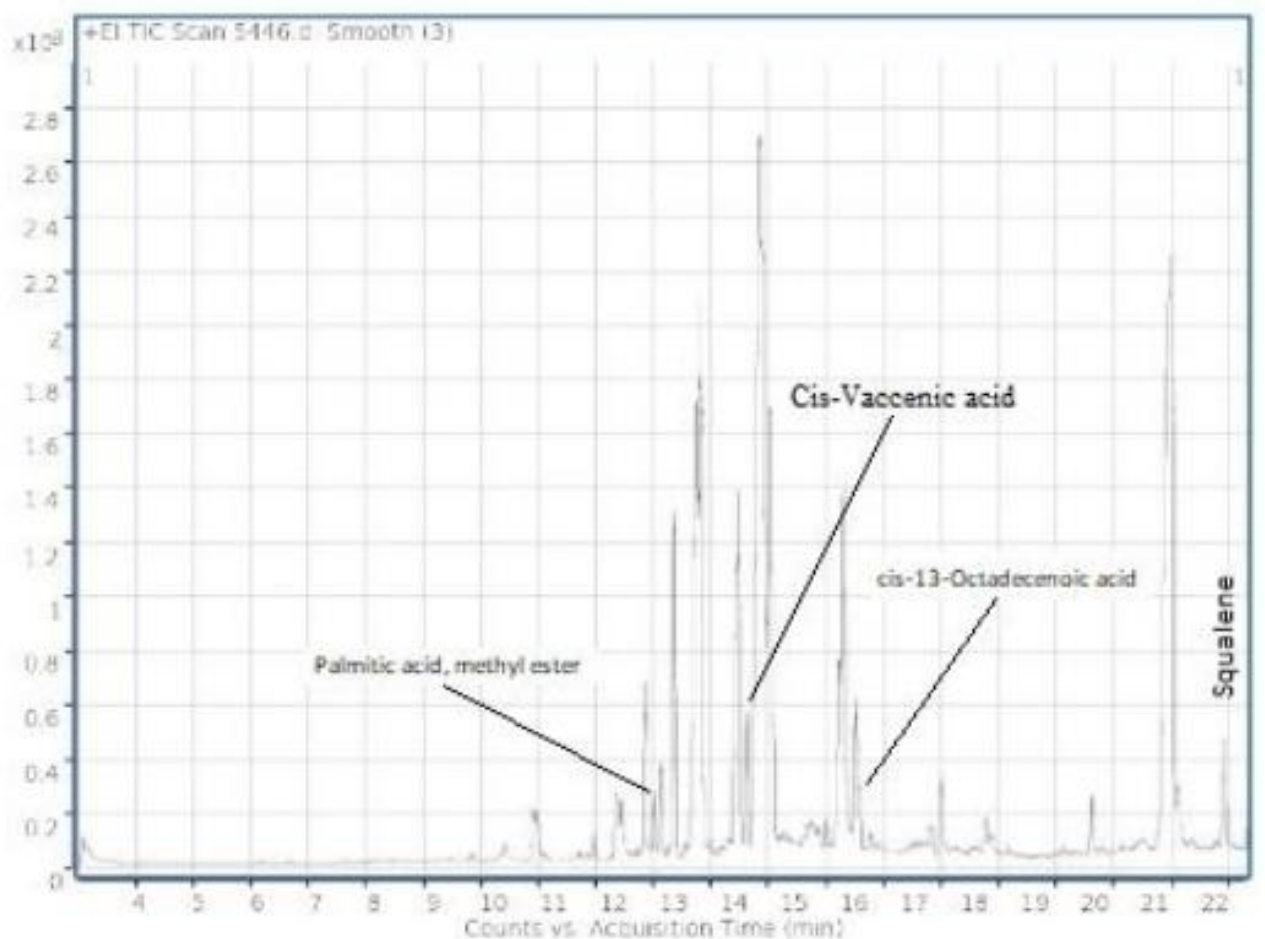

Fig. 1: GC-MS chromatograms of different identified compounds in chloroformic extract from Vangueria infausta leaves. 
Table 2: Serum lipid profile in C, HCD, HCD+LDCE, HCD+HDCE and HCD+ A- treated groups

\begin{tabular}{lcccccc}
\hline Group & $\begin{array}{c}\text { TG } \\
(\mathbf{m g} / \mathbf{d l})\end{array}$ & $\begin{array}{c}\text { TC } \\
(\mathbf{m g} / \mathbf{d l})\end{array}$ & $\begin{array}{c}\text { HDL-C } \\
(\mathbf{m g} / \mathbf{d l})\end{array}$ & $\begin{array}{c}\text { LDL-C } \\
(\mathbf{m g} / \mathbf{d l})\end{array}$ & $\begin{array}{c}\text { VLDL-C } \\
(\mathbf{m g} / \mathbf{d l})\end{array}$ & AI \\
\hline \multirow{2}{*}{$\mathbf{C}$} & $48.40 \pm$ & $60.60 \pm$ & $27.60 \pm$ & $27.75 \pm$ & $9.68 \pm$ & $1.33 \pm$ \\
& 2.01 & 1.96 & 1.74 & 0.94 & 0.4 & 0.14 \\
HCD & $86.66 \pm$ & $112.0 \pm$ & $19.50 \pm$ & $68.60 \pm$ & $17.50 \pm$ & $4.76 \pm$ \\
& $2.6^{\mathrm{a}}$ & $5.5^{\mathrm{a}}$ & $1.04^{\mathrm{a}}$ & $3.8^{\mathrm{a}}$ & $0.4^{\mathrm{a}}$ & $0.22^{\mathrm{a}}$ \\
HCD + LDCE & $70.0 \pm$ & $90.33 \pm$ & $18.0 \pm$ & $60.20 \pm$ & $15.20 \pm$ & $4.12 \pm$ \\
& $2.34^{\mathrm{ab}}$ & $2.6^{\mathrm{ab}}$ & $1.11^{\mathrm{a}}$ & $2.5^{\mathrm{a}}$ & $1.34^{\mathrm{a}}$ & $0.29^{\mathrm{a}}$ \\
HCD + HDCE & $57.20 \pm$ & $68.80 \pm$ & $25.40 \pm$ & $28.75 \pm$ & $11.44 \pm$ & $1.53 \pm$ \\
& $3.30^{\mathrm{bc}}$ & $2.99^{\mathrm{bc}}$ & $1.80^{\mathrm{bc}}$ & $2.01^{\mathrm{bc}}$ & $0.65^{\mathrm{bc}}$ & $0.09^{\mathrm{bc}}$ \\
HCD + A & $54.80 \pm$ & $63.20 \pm$ & $27.60 \pm$ & $27.00 \pm$ & $10.88 \pm$ & $1.42 \pm$ \\
& $2.68^{\mathrm{bc}}$ & $2.4^{\mathrm{bc}}$ & $1.35^{\mathrm{bc}}$ & $3.51^{\mathrm{bc}}$ & $0.49^{\mathrm{bc}}$ & $0.16^{\mathrm{bc}}$ \\
\hline
\end{tabular}

Results are expressed as mean \pm S.E.

${ }^{a} P<0.05$ :Significantly different from control group.

${ }^{\mathrm{b}} P<0.05$ :Significantly different from HCD treated group.

${ }^{\mathrm{c}} P<0.05$ :Significantly different from HCD+LDCE treated group.

C: Control

HCD: High cholesterol diet, HCD+LDCE: High cholesterol diet+ low dose of chloroformic extract

HCD+HDCE: High cholesterol diet + high dose of chloroformic extract , HCD + A: High cholesterol diet + Atorvastatin

\section{Effect of V. infausta extract treatment on serum Albumin, total proteins, ALT, AST, urea and creatinine, liver GSH and MDA}

Administration of HCD showed a significant increase in the serum AST activity, liver MDA and a decline in the liver GSH level in comparison with that of their matching control group, $P<0.05$. Both doses of $V$. infausta extract as well as the reference drug treatment caused a significant decrease in the serum AST activity as compared to that of HCD-treated group, $P<0.05$. While the high dose of the extract and the reference drug produced a significant decline in the liver MDA level and a significant increase in liver GSH when compared to that of HCD-treated rats, $P<0.05$, Neither HCD nor extract as well as the reference drug had no effect on the serum albumin, total proteins, ALT, urea and creatinine, Table (3).

Table 3: Serum ALT, AST, albumin, urea and creatinine in C, HCD, HCD+LDCE, HCD+HDCE and $\mathrm{HCD}+\mathrm{A}$-treated groups

\begin{tabular}{|c|c|c|c|c|c|c|c|c|}
\hline Group & $\begin{array}{l}\text { Albumin } \\
\text { (g/dl) }\end{array}$ & $\begin{array}{c}\text { Total } \\
\text { proteins } \\
(\mathrm{g} / \mathrm{dl})\end{array}$ & $\begin{array}{c}\text { ALT } \\
(\mathbf{U} / \mathbf{L})\end{array}$ & $\begin{array}{c}\text { AST } \\
(\mathbf{U} / \mathbf{L})\end{array}$ & $\begin{array}{c}\text { Urea } \\
(\mathrm{mg} / \mathrm{dl})\end{array}$ & $\begin{array}{c}\text { Creatinine } \\
(\mathrm{mg} / \mathrm{dl})\end{array}$ & $\begin{array}{c}\text { Liver } \\
\text { GSH } \\
\text { (nmol/mg } \\
\text { protein) }\end{array}$ & $\begin{array}{c}\text { Liver } \\
\text { MDA } \\
\text { (nmol/g } \\
\text { tissue) }\end{array}$ \\
\hline $\mathrm{C}$ & $\begin{array}{c}4.64 \pm \\
0.1\end{array}$ & $\begin{array}{c}6.64 \pm \\
0.15\end{array}$ & $\begin{array}{c}32.60 \pm \\
1.5\end{array}$ & $\begin{array}{l}48.20 \\
\pm 1.65\end{array}$ & $\begin{array}{c}39.40 \pm \\
1.69\end{array}$ & $\begin{array}{c}0.67 \\
\pm 0.03\end{array}$ & $\begin{array}{c}51.60 \pm \\
1.69\end{array}$ & $\begin{array}{c}6.02 \pm \\
0.28\end{array}$ \\
\hline HCD & $\begin{array}{c}4.30 \\
\pm 0.13\end{array}$ & $\begin{array}{c}6.12 \pm \\
0.14\end{array}$ & $\begin{array}{c}37.80 \pm \\
2.32\end{array}$ & $\begin{array}{c}56.20 \pm \\
2.57^{\mathrm{a}}\end{array}$ & $\begin{array}{c}47.00 \pm \\
3.65\end{array}$ & $\begin{array}{c}0.80 \\
\pm 0.03\end{array}$ & $\begin{array}{c}37.20 \\
\pm 2.12^{\mathrm{a}}\end{array}$ & $\begin{array}{c}7.58 \\
\pm 0.28^{\mathrm{a}}\end{array}$ \\
\hline HCD + LDCE & $\begin{array}{c}4.40 \\
\pm 0.16\end{array}$ & $\begin{array}{c}6.08 \pm \\
0.14\end{array}$ & $\begin{array}{c}40.75 \pm \\
2.48\end{array}$ & $\begin{array}{c}53.40 \pm \\
3.07^{\mathrm{b}}\end{array}$ & $\begin{array}{l}47.80 \\
\pm 2.78\end{array}$ & $\begin{array}{c}0.80 \\
\pm 0.02\end{array}$ & $\begin{array}{c}37.80 \pm \\
2.47^{\mathrm{a}}\end{array}$ & $\begin{array}{c}6.98 \pm \\
0.35^{\mathrm{a}}\end{array}$ \\
\hline HCD + HDCE & $\begin{array}{c}4.70 \pm \\
0.09\end{array}$ & $\begin{array}{c}6.36 \pm \\
0.1\end{array}$ & $\begin{array}{c}36.80 \pm \\
1.27\end{array}$ & $\begin{array}{c}48.20 \pm \\
1.06^{\mathrm{b}}\end{array}$ & $\begin{array}{c}42.00 \pm \\
1.92\end{array}$ & $\begin{array}{c}0.70 \pm \\
0.04\end{array}$ & $\begin{array}{c}45.00 \\
\pm 1.92^{\mathrm{abc}}\end{array}$ & $\begin{array}{c}6.18 \pm \\
0.36^{b}\end{array}$ \\
\hline $\mathbf{H C D}+\mathbf{A}$ & $\begin{array}{c}4.38 \pm \\
0.15\end{array}$ & $\begin{array}{c}6.22 \pm \\
0.11\end{array}$ & $\begin{array}{c}33.60 \pm \\
2.24\end{array}$ & $\begin{array}{c}49.40 \pm \\
2.15^{\mathrm{b}}\end{array}$ & $\begin{array}{c}40.20 \pm \\
2.84\end{array}$ & $\begin{array}{c}0.63 \pm \\
0.04\end{array}$ & $\begin{array}{c}48.20 \\
\pm 1.59^{\mathrm{bc}}\end{array}$ & $\begin{array}{l}5.92 \pm \\
0.37^{\mathrm{b}}\end{array}$ \\
\hline
\end{tabular}

Results are expressed as mean \pm S.E.

${ }^{a} P<0.05$ :Significantly different from control group.

${ }^{\mathrm{b}} P<0.05$ :Significantly different from HCD treated group.

${ }^{\mathrm{c}} P<0.05$ :Significantly different from HCD+LDCE treated group.

C: Control

HCD: High cholesterol diet, HCD+LDCE: High cholesterol diet+ low dose of chloroformic extract

HCD+HDCE: High cholesterol diet+ high dose of chloroformic extract

$\mathrm{HCD}+\mathrm{A}$ : High cholesterol diet+ Atorvastatin 


\section{Histopathological investigation:}

In control group, liver showing the normal histological structure of hepatic lobule from central vein and hepatocytes arranged in hepatic cords, Fig 2 a. On the other hand, in HCD treated rats, liver showing fatty change (Steatosis) of hepatocytes, congestion of central vein and fatty change of sporadic hepatocytes, cytoplasmic vacuolization of hepatocytes and congestion of hepatic sinusoids and portal infiltration with inflammatory cells, Fig 2 bandc. Regarding, HCD+ Low dose displaying congestion of central vein and fatty change of sporadic hepatocytes, Fig (2d). While in HCD + high dose, the liver showing no histopathological alterations and normal histological structure of hepatic lobule, Fig 2 e. While liver in HCD + A, revealing slight congestion of central vein and activation of Kupffer cells, Fig (2f). Severity of histopathological alterations in liver of different experimental groups are summarized in Table (4).
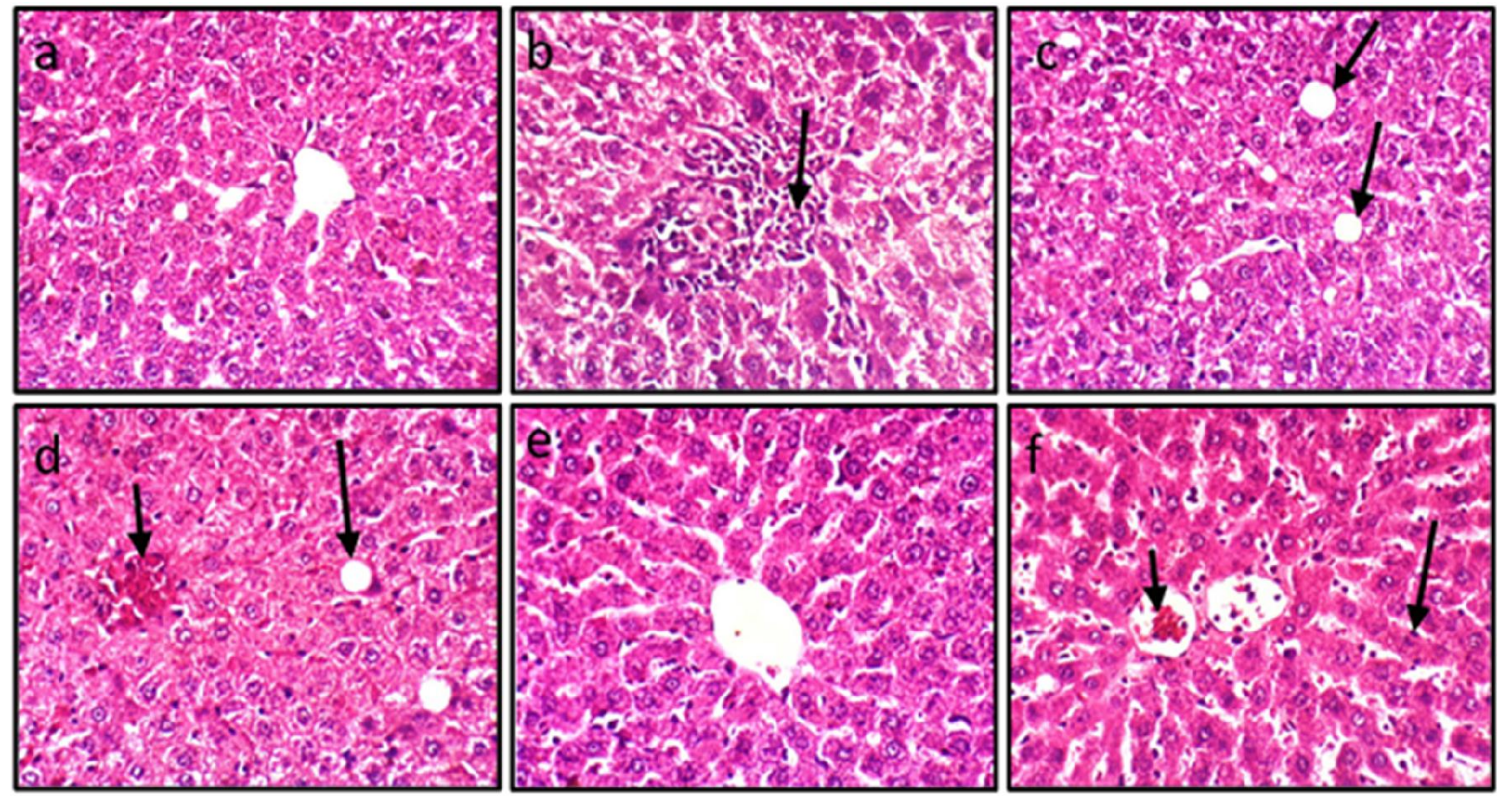

Fig. 2: Photomicrographs of liver tissue stained with (HE x400) a: In normal control; liver showing the normal histological structure of hepatic lobule from central vein and hepatocytes arranged in hepatic cords, bandc: HCD treated rats, liver showing fatty change (Steatosis) of hepatocytes, congestion of central vein, fatty change of sporadic hepatocytes, cytoplasmic vacuolization of hepatocytes, congestion of hepatic sinusoids and portal infiltration with inflammatory cells, d: HCD treated with low dose of chloroformic extract, showing congestion of central vein and fatty change of sporadic hepatocytes, e: HCD treated with high dose of chloroformic extract, the liver showing no histopathological alterations and normal histological structure of hepatic lobule, f: HCD treated with Atorvastatin (Reference drug) liver showing slight congestion of central vein and activation of Kupffer cells.

Table 4: Severity of histopathological alterations in liver of different experimental groups.

\begin{tabular}{lccccc}
\hline Histopathological lesion & C & HCD & HCD+ LDCE & HCD+ HDCE & HCD+ A \\
\hline Kupffer cells activation & 0 & 1 & 1 & 0 & 1 \\
Congestion of central vein and sinusoids & 0 & 2 & 2 & 0 & 2 \\
Cytoplasmic vacuolization of hepatocytes & 0 & 2 & 0 & 0 & 0 \\
Fatty change of hepatocytes & 0 & 2 & 1 & 0 & 0 \\
Portal infiltration with inflammatory cells & 0 & 2 & 0 & 0 & 0 \\
\hline
\end{tabular}

C:control, HCD: high cholesterol diet, HCD+ LDCE: high cholesterol diet $+125 \mathrm{mg} / \mathrm{kg}$ of chloroformic fraction, HCD+ HDCE: high cholesterol diet $+250 \mathrm{mg} / \mathrm{kg}$ of chloroformic extract, HCD $+\mathrm{A}$ : high cholesterol diet + Atorvastatin

(0): no change, (1) mild change, (2) moderate change, (3) severe change

C: Control

HCD: High cholesterol diet, HCD+LDCE: High cholesterol diet+ low dose of chloroformic extract

HCD+HDCE: High cholesterol diet+ high dose of chloroformic extract, HCD+A: High cholesterol diet+ Atorvastatin 


\section{Discussion}

Statins are 3-hydroxy-3- methylglutaryl coenzyme A (HMG-CoA) reductase inhibitors described by physicians to control hyperlipidemia and also for the prevention of coronary heart diseases. However, the therapeutic efficacy of the statins has been examined by many investigators with its prolonged use. Atorvastatin is the most commonly used HMG-CoA inhibitor to control or manage hyperlipidemia. Though, many previous investigations have reported several adverse effects such as liver toxicity and myopathy with the extended usage of atorvastatin (Choudhary et al., 2005). Therefore, the usage of plant and their products with medicinal importance has gained attention recently which are safe and effective (Choudhary et al., 2005).

The present work showed that feeding of rats with HCD for 8 weeks revealed a significant rise in plasma TG, TC and LDL-C accompanied by a significant decline in HDL-C level. It has been reported that an increase in dietary cholesterol intake in animals led to hypercholesterolemia. The treatment with the highest dose of the extract caused a normalization of the lipid profile pattern. This indicating a hypolipidemic activity of the chloroformic extract from $V$. infausta leaves. The activity of the extract showed no significant difference in comparison with that of the reference drug (Atorvastatin).

The results of the current study revealed that the $V$. infausta chloroformic extract contains saturated fatty acids $(30.25 \%)$, omega fatty acids (polyunsaturated fatty acids) (37.74\%), triterpene $(22.03 \%)$, hydrocarbons $(8.82 \%)$, and oxygenated compounds $(1.16 \%)$, Table $(1)$.

It has been reported that oils and specific fatty acids from plants are shown to provide medicinal benefits like antioxidant, anti-cholesterol, anti-hyperlipidemic and other activities for human beings (Zapolska, 2015).

Among the compounds that are exist in $V$. infausta chloroformic extract are triperpenes (represent $22.03 \%$, Table1); they have been reported to exert their hypolipidemic effects through reduction of serum cholesterol and triglyceride while raising the levels of HDL-c. In addition, ingestion of plant sterol and their esters has been reported to not only lower intestinal cholesterol absorption but decreased blood levels of the atherogenic LDL-c as well (Sudhahar et al., 2007, Brown et al., 2010).

Squalene is an example of triterpenes that identified in our work (Table1); it has been reported that supplementation of the diet with squalene can reduce cholesterol and triglyceride levels in animals (Kelly, 1999). This explains that the hypolipidemic activity of $V$. infausta extract in the current study may be attributed to the presence of triterpenes.

Moreover, in our work the hypolipidemic effects of $V$. infausta chloroformic extract could be attributed to the occurrence of oleic acid, (Table1) which is classified as a monounsaturated omega-9 fatty acid. In the last years, several studies described the involvement of olive oil to general health, partly due to its high oleic acid content (Panagiotakos et al., 2009, Terés et al., 2008, Bersamin et al., 2008) that was revealed to cause a reduction in cholesterol levels, and atherogenesis risk (Drosos and Moutsopoulos, 1995, Besler and Grimble 1995, Yaqoob, 1998, Mulrooney and Grimble, 1993). In addition, it has been reported that the potential of oleic acid to ameliorate cardiovascular risks may be associated to an improvement of serum lipoprotein profile (HDL-to-LDL) in patients with hypercholesterolemia (Zambón et al. 2000, Bemelmans et al., 2002).

Besides, another identified compound is the vaccenic acid (Table1), an omega-7 fatty acid, is found in Sea Buckthorn (Hippophae rhamnoides) oil. Trans-11 vaccenic acid [VA; 18:1(n-9)] is a positional and geometric isomer of oleic acid and is the precursor to conjugated linoleic acid in humans (Precht and Molkentin, 1999). Wang et al. reported that vaccenic acid supplementation leads to a significantly decreased the circulating plasma triglyceride concentration in JCR: LA-cp rats, an established rodent model of metabolic syndrome. Thus, it has been proposed that vaccenic acid may have a substantial hypotriglyceridemic benefits under conditions of dyslipidemia (Wang et al., 2008). Another class of identified compounds in this study is the oxygenated one, which comprises acyclic diterpene alcohol called phytol. It has been reported that phytol exhibits antioxidant activity through reduction of MDA formation and restored the depleted GSH content. Additionally, an alternative probability is that the increase in GSH levels could be secondary to a decrease in free radical production (Silva et al., 2014). 
In the present work, HCD-treated rats (Fig 2 bandc) liver showing fatty change (steatosis) of hepatocytes, congestion of central vein, fatty change of sporadic hepatocytes, cytoplasmic vacuolization of hepatocytes, congestion of hepatic sinusoids and portal infiltration with inflammatory cells. While in case of the treatment of HCD- animals with a high dose of the extract, the liver showing no histopathological alterations and normal histological structure of hepatic lobule, Fig (2 e). The absence of other histopathological lesions that further emphasized the biochemical consequences in the present study. The histopathological findings reinstated the membrane stabilizing, antioxidant, and anti-inflammatory potential of the high dose of extract. Hence, the chloroform extract can be considered as a therapeutic asset due to the reclamation of endogenous antioxidants and also via the supply of exogenous antioxidants in the form of triterpene (squalene) $22.03 \%$, Table (1). Squalene has been reported to own antioxidant properties. In vitro experimental evidence shows that squalene is a highly effective oxygen-scavenging agent. Following to oxidative stress as in case of sunlight exposure, squalene works as an efficient quencher of singlet oxygen and inhibits the corresponding lipid peroxidation at the human skin surface (Saint-Leger et al., 1986). Also, it has been reported that squalene is not particularly susceptible to peroxidation and is stable against attacks by peroxide radicals, suggesting that the chain reaction of lipid peroxidation is unlikely to be propagated with sufficient concentrations of squalene exist on the human skin surface (Kohno et al., 1995). On the other hand, Aioi et al., (1995) studied the effects of squalene on superoxide anion $\left(\mathrm{O}_{2}^{-}\right)$production in rats in order to elucidate the mechanism whereby this compound reduces erythema produced by $1 \%$ lauroylsarcosine (LS) ointment. LS in concentrations of $200 \sim 400 \mu \mathrm{g} / \mathrm{mL}$ instigated obvious production of $\mathrm{O}_{2}^{-}$from cultured keratinocytes and peritoneal exudate leukocytes. $\mathrm{O}_{2}^{-}$was significantly diminished by the addition of squalene at a concentration of $100 \mu \mathrm{g} / \mathrm{mL}$ (Aioi et al., 1995).

\section{Conclusion}

The present work revealed the anti-hyperlipidemic effect of the chloroformic extracts from $V$. infausta leaves. These findings provide some biochemical basis for the use of the $V$. infausta extract against hyperlipidemia. Further studies are required to explore the mechanism of the active components in the extract.

\section{Acknowledgements}

The author is grateful to Prof. Dr. Abeer Samir Temraz, Pharmacognosy Department, Faculty of Pharmacy for Girls, AlAzhar University, Egypt, for her kind cooperation and preparation of extracts.

\section{Competing interests:}

The authors declare that there is no conflict of interest.

\section{References}

Ahmed, S.F., E.N. Abd-Haleem, W.H. El-Tantawy, 2019. Evaluation of the anti-atherogenic potential of Egyptian artichoke leaf extract in hypercholesterolemic rats. Archives of Physiology and Biochemistry, 28:1-12. doi: 10.1080/13813455.2019.1669662. Online ahead of print. PMID: 31566004

Aioi, A., T. Shimizu, and K. Kuriyama, 1995. Effect of squalene on superoxide anion generation induced by a skin irritant, lauroylsarcosine. International Journal of Pharmaceutics, 113: 159164.

Behrens, B. and G. Karber, 1970. Detailed pharmacological testing of the substances. Chemotherapy of Neoplastic Diseases, 37.

Bemelmans, W.J., J. Broer, E.J. Feskens, A.J. Smit, F.A. Muskiet, J.D. Lefrandt, V.J. Bom, J.F. May, and B. Meyboom-De Jong, 2002. Effect of an increased intake of $\alpha$-linolenic acid and group nutritional education on cardiovascular risk factors: the Mediterranean Alpha-linolenic Enriched Groningen Dietary Intervention (MARGARIN) study. The American Journal of Clinical Nutrition, 75: 221-227.

Bersamin, A., B.R. Luick, I.B. King, J.S. Stern, and S. Zidenberg-Cherr, 2008. Westernizing diets influence fat intake, red blood cell fatty acid composition, and health in remote Alaskan Native 
communities in the center for Alaska Native health study. Journal of the American Dietetic Association, 108: 266-273.

Besler, H. and R. Grimble, 1995. Comparison of the modulatory influence of maize and olive oils and butter on metabolic responses to endotoxin in rats. Clinical Science, 88: 59-66.

Binno, S., 2016. European Guidelines on cardiovascular disease prevention in clinical practice-Web Addenda.

Brown, A.W., J. Hang, P.H. Dussault and T.P. Carr, 2010. Plant sterol and stanol substrate specificity of pancreatic cholesterol esterase. The Journal of Nutritional Biochemistry, 21: 736-740.

Chhabra, S., F. Uiso, and E. Mshiu, 1984. Phytochemical screening of Tanzanian medicinal plants. I. Journal of Ethnopharmacology, 11:157-179.

Choudhary, M.I., S. Naheed, S. Jalil, and J. Alam, 2005. Effects of ethanolic extract of Iris germanica on lipid profile of rats fed on a high-fat diet. Journal of Ethnopharmacology, 98: 217-220.

Clarke, A.T., P.C. Johnson, G.C. Hall, I. Ford and P.R. Mills, 2016. High dose atorvastatin associated with increased risk of significant hepatotoxicity in comparison to simvastatin in UK GPRD cohort. PLoS One, 11.

Drosos, A. and H. Moutsopoulos, 1995. Rheumatoid arthritis in Greece: clinical, serological and genetic considerations. Clinical and Experimental Rheumatology, 13: S7-12.

Ellman, G.L., 1959. Tissue sulfhydryl groups. Archives of Biochemistry and Biophysics, 82: 70-77.

El-Tantawy, W.H., A. Temraz, H.E. Hozaien, O.D. El-Gindi and K.F. Taha, 2015. Antihyperlipidemic activity of an extract from roots and rhizomes of Panicum repens L. on high cholesterol diet-induced hyperlipidemia in rats. Zeitschrift fur Naturforschung C, 70: 139-144.

El-Tantawy, W.H., W.A. Hassan, and N.M. Saied, 2011. Role of V. infausta extract on pancreatic and hepatic oxicity of lipopolyscacchride-treated rats. Journal of Pharmaceutical Research and Clinical Practice, Jan-March, 1(1): 62-75.

Friedewald, W.T., R.I. Levy, and D.S. Fredrickson, 1972. Estimation of the concentration of lowdensity lipoprotein cholesterol in plasma, without use of the preparative ultracentrifuge. Clinical Chemistry, 18: 499-502.

Kelly, G.S., 1999. Squalene and its potential clinical uses. Alternative medicine review: A Journal of Clinical Therapeutic, 4: 29-36.

Kohno, Y., Y. Egawa, S. Itoh, S.-I. Nagaoka, M. Takahashi, and K. Mukai, 1995. Kinetic study of quenching reaction of singlet oxygen and scavenging reaction of free radical by squalene in $n$ butanol. Biochimica et Biophysica Acta (BBA)-Lipids and Lipid Metabolism, 1256: 52-56.

Maroyi, A., 2018. Nutraceutical and Ethnopharmacological Properties of Vangueria infausta subsp. infausta. Molecules, 23(5): 1089; https://doi.org/10.3390/molecules23051089

Mulrooney, H.M. and R.F. Grimble, 1993. Influence of butter and of corn, coconut and fish oils on the effects of recombinant human tumour necrosis factor- $\alpha$ in rats. Clinical Science, 84: 105112.

Mutangadura, G.B., 2004. World health report 2002: reducing risks, promoting healthy life: world health organization, Geneva, 2002, 250 pages, US \$13.50, ISBN 9-2415-6207-2. Agricultural Economics, 30: 170-172.

Ohkawa, H., N. Ohishi, and K. Yagi, 1979. Assay for lipid peroxides in animal tissues by thiobarbituric acid reaction. Analytical Biochemistry, 95:351-358.

Panagiotakos, D.B., K. Dimakopoulou, K. Katsouyanni, T. Bellander, M. Grau, W. Koenig, T. Lanki, R. Pistelli, A. Schneider, and A. Peters, 2009. Mediterranean diet and inflammatory response in myocardial infarction survivors. International Journal of Epidemiology, 38: 856-866.

Precht, D. and J. Molkentin, 1999. C18: 1, C18: 2 and C18: 3 trans and cis fatty acid isomers including conjugated cis $\Delta 9$, trans $\Delta 11$ linoleic acid (CLA) as well as total fat composition of German human milk lipids. Food/Nahrung, 43: 233-244.

Saint-Leger, D., A. Bague, E. Lefebvre, E. Cohen, and M. Chivot, 1986. A possible role for squalene in the pathogenesis of acne. II. In vivo study of squalene oxides in skin surface and intracomedonal lipids of acne patients. British Journal of Dermatology, 114: 543-552.

Santana, P.M., M. Miranda, J.A. Payrol, M. Silva, V.Hernández, and E. Peralta, 2013. Gas chromatography-mass spectrometry study from the leaves fractions obtained of Vernonanthura patens (Kunth) H. Rob. International Journal of Organic Chemistry, 3, 105-109. 
Sehra, D., S. Sehra, and S.T. Sehra, 2017. Cardiovascular pleiotropic effects of statins and new onset diabetes: is there a common link: do we need to evaluate the role of KATP channels? Expert Opinion on Drug Safety, 16: 823-831.

Silva, R.O., F.B.M. Sousa, S.R. Damasceno, N.S. Carvalho, V.G. Silva, F.R.M. Oliveira, D.P. Sousa, K.S. Aragão, A.L. Barbosa, and R.M. Freitas, 2014. Phytol, a diterpene alcohol, inhibits the inflammatory response by reducing cytokine production and oxidative stress. Fundamental and Clinical Pharmacology, 28: 455-464.

Sudhahar, V., S.A. Kumar, P.T. Sudharsan, and P. Varalakshmi, 2007. Protective effect of lupeol and its ester on cardiac abnormalities in experimental hypercholesterolemia. Vascular Pharmacology, 46: 412-418.

Terés, S., G. Barceló-Coblijn, M. Benet, R. Alvarez, R. Bressani, J. Halver, and P. Escriba, 2008. Oleic acid content is responsible for the reduction in blood pressure induced by olive oil. Proceedings of the National Academy of Sciences, 105: 13811-13816.

Wang, Y., J. Lu, M.R. Ruth, S.D. Goruk, M.J. Reaney, D.R. Glimm, D.F. Vine, C.J. Field, and S.D. Proctor, 2008. Trans-11 vaccenic acid dietary supplementation induces hypolipidemic effects in JCR: LA-cp rats. The Journal of Nutrition, 138: 2117-2122.

Yaqoob, P., 1998. Monounsaturated fats and immune function. Proceedings of the Nutrition Society, $57,511-520$.

Zambón, D., J. Sabaté, S. Munoz, B. Campero, E. Casals, M. Merlos, J.C.Laguna, and E. Ros, 2000. Substituting walnuts for monounsaturated fat improves the serum lipid profile of hypercholesterolemic men and women: a randomized crossover trial. Annals of Internal Medicine, 132:538-546.

Zapolska, DD., D. Bryk, and W. Olejarz, 2015. Trans fatty acids and atherosclerosis-effects on inflammation and endothelial function. Nutrition and Food Sciences. 5:6 http://dx.doi.org/10.4172/2155-9600.1000426 